\title{
A novel nomogram to predict 90-day mortality of patients with sepsis
}

\section{Qingbo Zeng}

the 908th Hospital of Chinese PLA Logistical Support Force https://orcid.org/0000-0002-0742-125X

\section{Long-Ping $\mathrm{He}$}

908th hospital of Chinese PLA Logistical Support Force

\section{Nianqing Zhang}

NanChang Hongdou Hospital of TCM

\section{Qin-Wei Lin}

908th Hospital of Chinese PLA Logistical Support Force

lin-Cui Zhong

908th Hospital of Chinese PLA Longistical Support Force

Jing-Chun Song ( $\nabla$ songjingchun@126.com )

908th Hospital of Chinese PLA Longistical Support Force https://orcid.org/0000-0001-5869-5077

\section{Research}

Keywords: Sepsis, Mortality, Nomogram, Prediction, Lactate

Posted Date: April 7th, 2021

DOI: https://doi.org/10.21203/rs.3.rs-396188/v1

License: (c) (1) This work is licensed under a Creative Commons Attribution 4.0 International License.

Read Full License 


\section{Abstract \\ Background}

Sepsis is a prevalent disease among intensive care units and continues to be a frequent cause of death. This study aimed to establish a nomogram for mortality prediction in patients with sepsis.

\section{Methods}

We carried out a retrospective, single-center study based on 231 patients with sepsis and data was collected from May 2018 to October 2020. Patients were randomly split into training and validation cohorts. In the training cohort, multivariate logistic regression analysis and a stepwise algorithm were performed to identify risk factors, which were presented with a predictive nomogram. The receiver operating characteristic (ROC), calibration plots and decision curve analysis (DCA) were used to estimate the performance of the nomogram in both the training and validation cohorts.

\section{Results}

A total of 231 patients with sepsis were enrolled in the study, and the 90 -day mortality was $31.6 \%$. There were 161 and 70 cases in training and validation cohorts respectively. Statistical analyses showed that Age, international normalized ratio (INR), lactate (Lac), and thrombomodulin (TM) were the risk factors for 90 -day mortality. The area under the curve was $0.810(95 \% \mathrm{Cl}, 0.739$ to 0.881$)$ in training cohort and $0.813(95 \% \mathrm{Cl}, 0.708$ to 0.917$)$ in the validation cohort. Calibration curve showed good performance of this nomogram. Decision curve analysis demonstrated that the nomogram was clinical utility.

\section{Conclusion}

This nomogram offering a probability of mortality for a given patient can benefit outcome improvement and clinicians in making clinical decision.

\section{Introduction}

Sepsis is a life-threatening organ dysfunction initiated by the body's overwhelming response to infection [1]. Past decades witnessed sepsis as an important public health problem in the worldwide. Although significant advances have made in intensive care and supportive technology, there is high morbidity and mortality in sepsis. More unfortunately, it imposes heavy medical and financial burden on families and society. Fleischmann et al reported the incidence rate was 437 sepsis cases per 100000 person-years and the hospital mortality was $17 \%$ in the worldwide during the last decade [2]. Interestingly,in China, the mortality of sepsis is higher, and the incidence rate of sepsis in ICU is $20.6 \%$ [3]. The pathogenesis of sepsis is very complex, involving coagulation disorders, inflammation imbalance, immune dysfunction, 
mitochondrial damage and endothelial damage [4]. A better understanding of this disease's pathophysiological processes and identifying its high risk of short-term mortality are of great significance for medical intervention and prognostic improvement. There are numerous studies of risk factors for mortality in patients with sepsis [5-9], but most of them only pay attention to biomarkers involving inflammatory states and certain organ functions, and combining different risk factors to develop a predictive nomogram is rarely performed. Therefore, the main objective of this study is to construct a predictive nomogram in order to individually predict the probability of 90-day mortality in sepsis.

\section{Material And Methods}

\section{Patients and data collection}

A total of 231 patients who had been diagnosed with sepsis admitted to ICU in the $908^{\text {th }}$ People's Liberation Army Hospital, Nanchang, China, from May 2018 to October 2020. We selected adult patients (> 17 years of age) with a diagnosis of sepsis according to the Third International Consensus Definitions for Sepsis (Sepsis-3)[10]: (1) Patients with infection confirmed by the positive results of microbial cultivation and (2) the Sequential Organ Failure Assessment (SOFA) score $\geq 2$ [4]. Excluded were patients (1) under 18 years of age, (2) pregnancy, (3) hemorrhagic shock, (4) cancer, (5) acute coronary syndrome, (6) cardiopulmonary arrest. The following variables were retrospectively collected: baseline demographic data (age and gender), site of infection, comorbid conditions and mortality in 90 days. The severity of illness was evaluated by the Acute Physiology and Chronic Health Evaluation II (APACHE II) score [11] and the Sequential Organ Failure Assessment (SOFA) score[12] respectively, and they were calculated on a basis of clinical and laboratory values. The APACHE II score and SOFA score were calculated on the first day of ICU admission. The alanine transaminase (ALT), aspartate transaminase (AST), total bilirubin (TBil), serum creatinine ( $\mathrm{Cr}$ ), platelet count (PLT), prothrombin time (PT), international normalized ratio (INR), activated partial thrombin time (APTT), fibrinogen (FIB), thrombin time (TT), D-dimer, fibrinogen degradation product (FDP), thrombin-antithrombin complex (TAT), a2-plasmininhibitor-plasmin complex (PIC), thrombomodulin (TM), and tissue plasminogen activator-inhibitor complex (t-PAIC), were recorded. Other clinical variables, such as mean arterial pressure (MAP), temperature, heart rate, hemoglobin(HB), potential of hydrogen $(\mathrm{PH})$, arterial partial oxygen pressure ( $\mathrm{PaO} 2)$, arterial partial pressure of carbon dioxide (PaCO2) and lactate (Lac), were also recorded.

\section{Study design}

\section{Statistical analysis}

Data for continuous variables were presented as means \pm standard deviation or median with interquartile range (IQR). They were compared using Student's t-test (normal distribution) or Mann-Whitney (nonnormal distribution). Categorical variables, expressed as counts and percentages, were compared using c2 test or Fisher's exact test. The variance inflation factor (VIF) was used to test collinearity between continuous variables, and an arithmetic square root of VIF $\leq 10$ was regarded as non-collinearity. Clinical 
variables in the training cohort were entered into multivariate logistic regression analysis and backward step-wise selection was applied by using the likelihood ratio test with Akaike's information criterion as the stopping rule [13]. In order to provide clinicians with a quantitative tool to predict 90-day death of sepsis, we built the predictive nomogram on the basis of multivariable logistic analysis in the training cohort. The performance of this nomogram was composed of calibration and discrimination. Calibration curves were used to evaluate the calibration of the predictive model, accompanied with the Hosmer-Lemeshow test. The discriminative ability of the predictive nomogram was assessed by a receiver operating characteristic (ROC) curve. For clinical usefulness, net benefit was examined in both of the training and validation cohorts by decision curve analysis (DCA). All the statistical analyses were performed with $R$ version 4.0.1 (R Core Team, Vienna, Austria) and SPSS 25.0 software (SPSS Inc, Chicago, IL, USA). The two-sided $P$ values $<0.05$ were considered statistically significant.

\section{Results}

\section{Clinical characteristics of patients}

After screening by the inclusion and exclusion criteria, a total of 231 patients were included into the study. For these cases, the median age was 70 years old (range from 18 to 96 years old) and males accounted for $61.9 \%$. A total of 73 patients passed away within 3 month during the study period, resulting in the mortality of $31.6 \%$. The survival patients generally had lower level of t-PAIC, TAT, PT, INR, APTT, TT, FDP, Ddimer, Creatinine, Lac, Heartrate, SOFA, APACHEII, and higher levels of PLT, HB, and PaO2 in the two cohorts. Besides, the survival patients exhibited higher level of serum $\mathrm{PH}$ value in validation cohort. The other detailed clinical characteristics and results of univariate analysis are shown in Table 1.

Table1 Patients' baseline characteristics at ICU admission 


\begin{tabular}{|c|c|c|c|c|c|c|}
\hline \multirow{3}{*}{$\begin{array}{l}\text { Clinical } \\
\text { characteristics }\end{array}$} & \multicolumn{3}{|c|}{ Training cohort } & \multicolumn{3}{|c|}{ Validation cohort } \\
\hline & $\begin{array}{l}\text { Survival } \\
\text { patients }\end{array}$ & $\begin{array}{l}\text { Non-survival } \\
\text { patients }\end{array}$ & $\begin{array}{l}\mathrm{p} \\
\text { value }\end{array}$ & $\begin{array}{l}\text { Survival } \\
\text { patients }\end{array}$ & $\begin{array}{l}\text { Non-survival } \\
\text { patients }(n=24)\end{array}$ & $\begin{array}{l}\mathrm{p} \\
\text { value }\end{array}$ \\
\hline & $(n=112)$ & $(n=49)$ & & $(n=46)$ & & \\
\hline Male, n (\%) & $69(61.6)$ & $30(61.2 \rrbracket$ & 0.963 & $29(63.0)$ & $15(62.5)$ & 0.964 \\
\hline $\begin{array}{l}\text { Age } \geq 57(y), n \\
(\%)\end{array}$ & $47(42.0)$ & $32(65.3)$ & 0.006 & $30(65.2)$ & $22(91.7)$ & 0.016 \\
\hline \multicolumn{7}{|l|}{ Comorbidity } \\
\hline Diabetes, n (\%) & $17(15.2)$ & $10(20.4)$ & 0.414 & $17(37.0)$ & $9(37.5)$ & 0.964 \\
\hline $\begin{array}{l}\text { Hypertension, } n \\
\text { (\%) }\end{array}$ & $42(37.5)$ & $26(53.1)$ & 0.066 & $21(45.7)$ & $12(50.0)$ & 0.729 \\
\hline COPD, n (\%) & $6(5.4)$ & $6(12.2)$ & 0.126 & $8(17.4)$ & $6(25.0)$ & 0.450 \\
\hline CKD, n (\%) & $10(8.9)$ & $6(12.2)$ & 0.518 & $2(4.3)$ & $3(12.5)$ & 0.209 \\
\hline \multicolumn{7}{|l|}{ Source of infection } \\
\hline Pulmonary, n (\%) & $71(63.4)$ & $33(67.3)$ & 0.629 & $27(58.7)$ & 19(71.2) & 0.087 \\
\hline $\begin{array}{l}\text { Urinary tract, } \mathrm{n} \\
(\%)\end{array}$ & $8(7.1)$ & $1(2.0)$ & 0.195 & $5(10.9)$ & $0(0)$ & 0.094 \\
\hline Abdominal, n (\%) & $27(24.1)$ & $14(28.6)$ & 0.550 & 13(28.3) & $3(12.5)$ & 0.136 \\
\hline Skin (\%), n (\%) & $6(5.4)$ & $2(4.1)$ & 0.732 & $2(4.3)$ & $1(4.2)$ & 0.972 \\
\hline $\begin{array}{l}\mathrm{TM} \geq \\
\text { 13.1(TU/mL), n } \\
(\%)\end{array}$ & $17(15.2)$ & $22(44.9)$ & 0.000 & $17(37.0)$ & 17(70.8) & 0.007 \\
\hline TAT(ng/ml) & $\begin{array}{l}8.2(4.6- \\
18.0)\end{array}$ & $\begin{array}{l}17.2(5.7- \\
46.8)\end{array}$ & 0.002 & $\begin{array}{l}8.7(5.6- \\
17.0)\end{array}$ & $13.4(6.2-30.9)$ & 0.162 \\
\hline PIC(ug/mL) & $\begin{array}{l}1.16(0.62- \\
2.16)\end{array}$ & $\begin{array}{l}1.04(0.57- \\
2.28)\end{array}$ & 0.742 & $\begin{array}{l}1.10(0.75- \\
1.48)\end{array}$ & $1.43(0.69-2.83)$ & 0.421 \\
\hline t-PAIC(ng/ml) & $\begin{array}{l}12.2(7.6- \\
24.1)\end{array}$ & $\begin{array}{l}21.7(11.3- \\
41.7)\end{array}$ & 0.003 & $\begin{array}{l}14.2(9.4- \\
23.9)\end{array}$ & $21.3(13.8-47.1)$ & 0.020 \\
\hline PT (s) & $\begin{array}{l}14.2(12.7- \\
16.2)\end{array}$ & $\begin{array}{l}16.4(14.0- \\
21.4)\end{array}$ & 0.000 & $\begin{array}{l}13.7(13- \\
15.3)\end{array}$ & 15(13.6-19.6) & 0.008 \\
\hline INR & $\begin{array}{l}1.2(1.1- \\
1.3)\end{array}$ & $1.4(1.2-1.8)$ & 0.000 & $\begin{array}{l}1.14(1.08- \\
1.27)\end{array}$ & $1.25(1.13-1.60)$ & 0.008 \\
\hline APTT (s) & $\begin{array}{l}31.6(26.6- \\
38.4)\end{array}$ & $\begin{array}{l}37.4(32.0- \\
47.7)\end{array}$ & 0.000 & $\begin{array}{l}31.4(26.7- \\
40.5)\end{array}$ & $33.9(29.2-48.7)$ & 0.087 \\
\hline
\end{tabular}




\begin{tabular}{|c|c|c|c|c|c|c|}
\hline FIB (s) & $2.9 \pm 1.09$ & $2.6 \pm 1.2$ & 0.143 & $2.9 \pm 0.9$ & $2.7 \pm 1.3$ & 0.308 \\
\hline TT (s) & $\begin{array}{l}15.8(14.5- \\
17.3)\end{array}$ & $\begin{array}{l}17.2(14.8- \\
18.7)\end{array}$ & 0.003 & $\begin{array}{l}15.5(14.0- \\
17.4)\end{array}$ & 16.8(14.9-19.4) & 0.070 \\
\hline $\mathrm{FDP}(\mu \mathrm{g} / \mathrm{L})$ & $\begin{array}{l}8.69(3.67- \\
18.92)\end{array}$ & $\begin{array}{l}14.45(4.53- \\
38.00)\end{array}$ & 0.030 & $\begin{array}{l}7.56(4.51- \\
13.12)\end{array}$ & $11.37(6.99-27.95)$ & 0.033 \\
\hline D-dimer( $\mu \mathrm{g} / \mathrm{L})$ & $\begin{array}{l}2.59(1.03- \\
5.97)\end{array}$ & $\begin{array}{l}4.91(1.65- \\
11.00)\end{array}$ & 0.016 & $\begin{array}{l}2.19(0.87- \\
4.53)\end{array}$ & $3.19(2.54-7.76)$ & 0.015 \\
\hline Platelet(× 109/L) & $179 \pm 90$ & $138 \pm 94$ & 0.010 & $182 \pm 108$ & $209 \pm 128$ & 0.358 \\
\hline Hemoglobin $(\mathrm{g} / \mathrm{L})$ & $111 \pm 29$ & $100 \pm 31$ & 0.038 & $109 \pm 31$ & $104 \pm 31$ & 0.525 \\
\hline $\mathrm{ALT}(\mathrm{U} / \mathrm{L})$ & $\begin{array}{l}31.9(12.9- \\
73.5)\end{array}$ & $\begin{array}{l}21.5(13.3- \\
116.8)\end{array}$ & 0.597 & $\begin{array}{l}27.3(13.3- \\
58.7)\end{array}$ & 29.6(11.1-64.2) & 0.921 \\
\hline AST(U/L) & $\begin{array}{l}43.0(23.3- \\
84.3)\end{array}$ & $\begin{array}{l}42.1(26.4- \\
131.2)\end{array}$ & 0.483 & $\begin{array}{l}33.2(19.8- \\
72.5)\end{array}$ & $30.3(19.1-76.7)$ & 0.843 \\
\hline TBil(umol/L) & $\begin{array}{l}13.5(7.9- \\
22.5)\end{array}$ & $\begin{array}{l}13.9(7.4- \\
32.5)\end{array}$ & 0.514 & $\begin{array}{l}14.5(6.8- \\
23.4)\end{array}$ & 17.6(10.9-28.1) & 0.192 \\
\hline $\mathrm{Cr}(\mu \mathrm{mol} / \mathrm{ml})$ & $\begin{array}{l}92.6(62.3- \\
163.8)\end{array}$ & $\begin{array}{l}136(76.5- \\
241.4)\end{array}$ & 0.017 & $\begin{array}{l}70.3(54.5- \\
132.5)\end{array}$ & $113.4(78.3-150.0)$ & 0.056 \\
\hline Temperature $\left({ }^{\circ} \mathrm{C}\right)$ & $\begin{array}{l}36.7(36.5- \\
37.5)\end{array}$ & $\begin{array}{l}36.6(36.3- \\
37.3)\end{array}$ & 0.350 & $\begin{array}{l}36.7(36.2- \\
37.3)\end{array}$ & $36.4(36.0-36.8)$ & 0.176 \\
\hline Heart rate(min-1) & $96 \pm 20$ & $106 \pm 25$ & 0.013 & $98 \pm 26$ & $107 \pm 26$ & 0.179 \\
\hline MAP $(\mathrm{mmHg})$ & $90 \pm 17$ & $88 \pm 22$ & 0.547 & $91 \pm 17$ & $87 \pm 18$ & 0.352 \\
\hline SOFA & $7(5-10)$ & $9(7-15)$ & 0.000 & $7(5-10)$ & $9(6-13)$ & 0.065 \\
\hline APACHEII & $21 \pm 6$ & $24 \pm 6$ & 0.008 & $22 \pm 7$ & $27 \pm 7$ & 0.004 \\
\hline $\mathrm{PH}$ & $\begin{array}{l}7.41(7.35- \\
7.45)\end{array}$ & $\begin{array}{l}7.38(7.29- \\
7.50)\end{array}$ & 0.133 & $\begin{array}{l}7.42(7.34- \\
7.49)\end{array}$ & 7.29(7.19-7.43) & 0.006 \\
\hline $\mathrm{PaCO} 2(\mathrm{mmHg})$ & $36(31-42)$ & $34(29-40)$ & 0.149 & $34(28-41)$ & $39(32-46)$ & 0.040 \\
\hline $\mathrm{PaO} 2(\mathrm{mmHg})$ & $\begin{array}{l}110(81- \\
157)\end{array}$ & $93(64-140)$ & 0.017 & $\begin{array}{l}112(80- \\
167)\end{array}$ & $97.1(64-152)$ & 0.366 \\
\hline Lac (mmol/L) & $1.7(1-3.2)$ & $3.2(1.5-6.6)$ & 0.000 & $\begin{array}{l}2.0(1.2- \\
3.3)\end{array}$ & $3.8(1.8-9.5)$ & 0.010 \\
\hline
\end{tabular}

COPD chronic obstructive pulmonary disease, $C K D$ chronic kindey disease, TM thrombomodulin, TAT thrombin-antithrombin complex, PIC a2-plasmininhibitor-plasmin complex, $t P A / C$ tissue plasminogen activator-inhibitor complex $\triangle P T$ prothrombin time, $A P T T$ activated partial thrombin time, FIB fibrinogen, INR international normalized ratio, $T T$ thrombin time, FDP fibrinogen degradation product, $A L T$ alanine transaminase, AST aspartate transaminase, TBil total bilirubin, MAP mean arterial pressure, SOFA 
Sequential Organ Failure Assessment, APACHEIl Acute Physiology and Chronic Health Evaluation II, $P H$ potential of hydrogen, $\mathrm{PaO}_{2}$ arterial partial oxygen pressure, $\mathrm{PaCO}_{2}$ arterial partial pressure of carbon dioxide, Laclactate.

\section{Development of an Individualized Prediction Model}

Multiple logistic regression analysis identified the age, INR, Lac, and TM as independent predictors (Table 2). This model that contained the above independent predictors was developed and presented as the nomogram (Fig 1).

Table 2 Factors independently associated with 90 -day mortality of patients with sepsis in the multivariate logistic analysis

\begin{tabular}{|llll|}
\hline Variables & OR & $95 \% \mathrm{Cl}$ & P value \\
\hline Age $(\geq 57$ y vs. $<57$ y $)$ & 1.20 & $0.36-2.04$ & 0.005 \\
\hline $\mathrm{TM}(\geq 13.1 \mathrm{TU} / \mathrm{mL}$ vs. $<13.1 \mathrm{TU} / \mathrm{mL})$ & 1.30 & $0.39-2.21$ & 0.005 \\
\hline $\mathrm{INR}$ & 1.52 & $0.23-2.80$ & 0.021 \\
\hline $\mathrm{Lac}(\mathrm{mmol} / \mathrm{L})$ & 0.17 & $0.04-0.29$ & 0.008 \\
\hline
\end{tabular}

INR international normalized ratio, TM thrombomodulin, Lac lactate,

\section{Validation of the prediction nomogram}

The calibration curve of this nomogram for the probability of 90-day mortality demonstrated an excellent conformity between prediction and observation in the training and validation cohorts although the logistic calibration curve and nonparametric curve slightly deviated from ideal line (Fig 3). In addition, the Hosmer-Lemeshow test showed a nonsignificant statistic $(P>0.05)$, which indicated that there was no violation of perfect fit.

\section{Clinical application of the nomogram}

The decision curve analysis (DCA) was performed in the training and validation cohorts $\llbracket$ in order to assess the clinical usefulness of the predictive nomogram. It is presented in Fig. $4 A$ and $B$, respectively. The decision curve showed that the nomogram could provide a good clinical utility. The result showed that if the threshold probability of a patient or doctor is approximate $>15 \%$, using the nomogram to predict 90-day death can reap more benefit than either the treat-all-patients scheme or the treat-none scheme.

\section{Discussion}


In this study, the 90 -day mortality was $31.6 \%$, which is higher than other studies [2, 3, 5]. The major reason for this difference in mortality may be different follow-up days. Nomograms which base on a combination of risk factors are frequently used to estimate prognosis and it can well show the significance of factors in the outcome. Risk factors for short-term mortality in sepsis have been studied in recent decades, but a large number of previous reports have only described potential risk factors without developing nomogram, resulting in predicting prognosis inaccurately. In this study, we created a nomogram to predict 90-day mortality for patients with sepsis. This nomogram incorporates age, INR, Lac, and TM, which were identified by multiple logistic regression analysis. As a result, the usefulness of this nomogram for prognosis in patients with sepsis has the advantage of accurate prediction and the outcome prediction can be more individualized.

We all know that coagulopathy is frequently observed in sepsis [14] and plays a vital role in multiple organ dysfunction syndrome [15]. Lyons et al reported that the increased severity of coagulopathy can lead to increased mortality [16]. Besides, hemostasis-related parameter has also been reported as a predictor of sepsis-related mortality [17-19]. In this study, we found that the INR value in death group was significantly higher than in survival group and it was an independent factor for 90-day death identified by multivariate analysis. However, it is less likely to use INR alone to accurately assess the outcomes of sepsis patients [5].

Serum lactate levels are often considered as a marker of tissue hypoxia [20] and it is commonly used to estimate prognosis and guide clinical treatment [21]. Interestingly, the higher level of lactate has always been found in critically ill patients, particularly in sepsis and septic shock patients [22]. Previous studies revealed that lactate levels correlate strongly and positively with disease severity and mortality in the context of sepsis [23-25]. Additionally, the sepsis-3.0 guidelines recommended persistence of a serum lactate more than $2 \mathrm{mmol} / \mathrm{L}$ as a new criterion for the clinically identification of septic shock [10]. In agreement with previous studies, we found that the lactate level in death group was significantly higher than in survival group and presented as an independent risk factor for sepsis mortality.

Increased levels of serum TM have been found in both pediatric and adult sepsis [26, 27]. During sepsis, the primary site of deterioration is endothelium because it is damaged directly by mass proinflammatory cytokines [28]. TM, an integral endothelial cell membrane protein, is cleaved and released into the bloodstream during sepsis and septic shock, thereby leading to elevated levels of serum TM $[29,30]$. Additionally, previous studies have shown that increased serum TM level is associated with disease severity and a high risk of death in sepsis [27, 30]. In this study, we observed that the TM levels measured were significantly increased in death group when compared with the survival group, and the higher TM levels were associated with poor outcome.

ROC analysis is a very important method to evaluate the performance of a model [31]. In this study, the ROC curve showed that the AUC was 0.810 in the training cohort and 0.812 in the validation cohort, which indicates that our predictive model has a good ability to predict. In other word, the predictive model has good discrimination. However, an AUC alone to assess a model in improving clinical decision-making is 
inadequate. Therefore, decision curve analysis was used to further assess the performance of the model because it can evaluate the net benefit of model-assisted decisions under different threshold probabilities. In this study, the decision curve showed that treatment directed by nomogram was obviously superior to the treat-all-patients project or the treat-none project. It's prognosis predicted by this nomogram that can add more net benefit for patients with sepsis in the training and validation cohorts. Besides, the calibration curve showed that the model was a good fit. Overall, all of these findings put together indicate that the predictive nomogram is highly accurate in predicting sepsis-related mortality.

Some potential limitations of this study should be noted. First, this database contained data obtained from a single center, and the size of this study population is small. Therefore, the results obtained may have limited external validity because we did not use an external population to validate the predictive nomogram. Another limitation of this study is that the data was collected in a retrospective manner. In the future, a multicenter study with external validation should be performed to further confirm performance of the nomogram.

\section{Conclusion}

We developed a novel predictive nomogram that incorporated patients'age, INR, Lac, and TM, which can be conveniently used to facilitate accurate prediction of the 90-day mortality in patients with sepsis.

\section{Abbreviations}

COPD: chronic obstructive pulmonary disease; CKD: chronic kindey disease; TM: thrombomodulin; TAT: thrombin-antithrombin complex; PIC: a2-plasmininhibitor-plasmin complex; tPAIC: tissue plasminogen activator-inhibitor complex; PT: prothrombin time; APTT: activated partial thrombin time; FIB: fibrinogen; INR: international normalized ratio; TT: thrombin time; FDP: fibrinogen degradation product; ALT: alanine transaminase; AST: aspartate transaminase; TBil: total bilirubin; MAP: mean arterial pressure; SOFA: Sequential Organ Failure Assessment; APACHEII: Acute Physiology and Chronic Health Evaluation II; PH: potential of hydrogen; $\mathrm{PaO}_{2}$ : arterial partial oxygen pressure; $\mathrm{PaCO} 2$ : arterial partial pressure of carbon dioxide; Lac: lactate; IQR: median with interquartile range; VIF: variance inflation factor; DCA: decision curve analysis; ROC: receiver operating characteristic; 95\% Cl: 95\% Confidence interval; ICU: intensive care unit.

\section{Declarations}

\section{Acknowledgements}

None

\section{Authors' contributions}


QBZ, LPH and JCS designed this study. LPH collected the data. NQZ, LCZ and QWL were responsible for the statistical analysis. QBZ and LPH were the first writing authors of the manuscript. JCS finalized this manuscript. The authors read and approved the final manuscript.

\section{Authors' information}

1. Intensive Care Unit $\$ the $908^{\text {th }}$ Hospital of Chinese PLA Logistical Support Force $₫$ Nanchang $330002 \rrbracket$

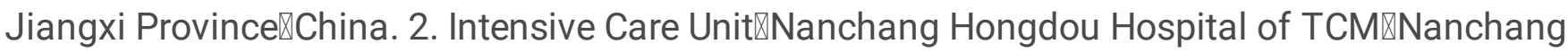
330002ðJiangxi Province『China.

\section{Funding}

None

\section{Availability of data and materials}

The raw data supporting the conclusions of this article will be made available by the authors, without undue reservation.

\section{Ethics approval and consent to participate}

The study was approved by the Ethics Committee of all the study centers. Written informed consent was waived by the Ethics Commission of $908^{\text {th }}$ hospital.

Competing interests

The authors declare that they have no competing interests.

\section{Consent for publication}

No individual participant data is reported that would require consent to publish from the participant.

\section{References}

1. Rhodes A, Evans LE, Alhazzani W, Levy MM, Antonelli M, Ferrer R, et al. Surviving sepsis campaign: International guidelines for management of sepsis and septic shock: 2016. Crit. Care Med. 2017; 45:486-552.

2. Fleischmann C, Scherag A, Adhikari NK, Hartog CS, Tsaganos T, Schlattmann P, et al. Assesment of Global Incidence and Mortality of Hsopital-treated Sepsis. Current Estimate and Limitations. Am J Respir Crit Care Med. 2016, 193(3):259-72.

3. Xie J, Wang H, Kang Y, Zhou L, Liu Z, Qin B, et al. The Epidemiology of Sepsis in Chinese ICUs: A National Cross-Sectional Survey. Crit. Care Med.2020; 48(3):e209-e218. 
4. Huang M, Cai S, Su J. The Pathogenesis of Sepsis and Potential Therapeutic Targets. Int J Mol Sci. 2019; 20(21):5376.

5. Liu J, Bai C, Li B, Shan A, Shi F, Yao C, et al. Mortality prediction using a novel combination of biomarkers in the first day of sepsis in intensive care units. Sci Rep. 2021; 11(1):1275.

6. Johansen ME, Johansson PI, Ostrowski SR, Bestle MH, Hein L, Jensen AL, et al. Profound endothelial damage predicts impending organ failure and death in sepsis. Semin Thromb Hemost. 2015; 41(1):16-25.

7. Wang M, Jiang L, Zhu B, Li W, Du B, Kang Y, et al. The Prevalence, Risk Factors, and Outcomes of Sepsis in Critically III Patients in China: A Multicenter Prospective Cohort Study. Front Med (Lausanne). 2020; 7:593808.

8. Bateman RM, Sharpe MD, Jagger JE, Ellis CG, Solé-Violán J, López-Rodríguez M, et al. Risk Factors for Mortality, Intensive Care Unit Admission, and Bacteremia in Patients Suspected of Sepsis at the Emergency Department: A Prospective Cohort Study. Open Forum Infect Dis. 2020; 8(1):ofaa594.

9. Innocenti F, Meo F, Giacomelli I, Tozzi C, Ralli ML, Donnini C, et al. Prognostic value of serial lactate levels in septic patients with and without shock. Intern. Emerg. Med. 2019; 14: 1321-30.

10. Singer M, Deutschman CS, Seymour CW, Shankar-Hari M, Annane D, Bauer M, et al. The third internationalconsensus definitions for sepsis and septic shock (Sepsis-3). JAMA. 2016;315(8).

11. Knaus WA, Draper EA, Wagner DP, Zimmerman JE. APACHE II: a severity of disease classification system. Crit Care Med. 1985, 13:818-29.

12. Raith, E. P. et al. Prognostic accuracy of the SOFA score, SIRS criteria, and qSOFA score for inhospital mortality among adults with suspected infection admitted to the intensive care unit. JAMA .2017; 317: 290-300.

13. Collins GS, Reitsma JB, Altman DG, Moons KG. Transparent reporting of a multivariable prediction model for individual prognosis or diagnosis (TRIPOD):The TRIPOD statement. BMJ. 2015;350: g7594.

14. Perner A, Rhodes A, Venkatesh B, Angus DC, Martin-Loeches I, Preiser JC, et al. Sepsis: Frontiers in supportive care, organisation and research. Intensive Care Med. 2017; 43:496-508.

15. Lelubre, C. \& Vincent, J. L. Mechanisms and treatment of organ failure in sepsis. Nat. Rev. Nephrol. 2018;14: 417-27.

16. Lyons PG, Micek ST, Hampton N, Kollef MH. Sepsis-Associated Coagulopathy Severity Predicts Hospital Mortality. Crit Care Med. 2018; 46(5):736-742.

17. Innocenti F, Gori AM, Giusti B, Tozzi C, Donnini C, Meo F, et al. Prognostic value of sepsis-induced coagulation abnormalities: an early assessment in the emergency department. Intern Emerg Med. 2019; 14(3):459-466.

18. Benediktsson S, Frigyesi A, Kander T. Routine coagulation tests on ICU admission are associated with mortality in sepsis: an observational study . Acta Anaesthesiol Scand. 2017;61(7):790-6. 
19. Iba T, Nisio MD, Levy JH, Kitamura N, Thachil J. New criteria for sepsis-induced coagulopathy (SIC) following the revised sepsis definition: a retrospective analysis of a nationwide survey. BMJ Open. 2017; 7(9):1-6.

20. Nolt B, Tu F, Wang X, Ha T, Winter R, Williams DL, et al. Lactate and Immunosuppression in Sepsis. Shock. 2018; 49(2):120-5.

21. Suetrong B, Walley KR. Lactic Acidosis in Sepsis: It's Not All Anaerobic: Implications for Diagnosis and Management. Chest. 2016; 149(1):252-61.

22. Nguyen HB, Rivers EP, Knoblich BP, Jacobsen G, Muzzin A, Ressler JA, et al. Early lactate clearance is associated with improved outcome in severe sepsis and septic shock. Crit Care Med. 2004; 32(8):1637-42.

23. Wacharasint P, Nakada TA, Boyd JH, Russell JA, Walley KR. Normal-range blood lactate concentration in septic shock is prognostic and predictive. Shock. 2012; 38(1):4-10.

24. Rishu AH, Khan R, Al-Dorzi HM, Tamim HM, Al-Qahtani S, Al-Ghamdi G, et al. Even mild hyperlactatemia is associated with increased mortality in critically ill patients. Crit Care. 2013;17:R197.

25. Liu Z, Meng Z, Li Y, Zhao J, Wu S, Gou S, et al. Prognostic accuracy of the serum lactate level, the SOFA score and the qSOFA score for mortality among adults with Sepsis. Scand J Trauma Resusc Emerg Med. 2019; 27(1):51.

26. Lin JJ, Hsiao HJ, Chan OW, Wang Y, Hsia SH, Chiu CH. Increased serum thrombomodulin level is associated with disease severity and mortality in pediatric sepsis. PLoS One. 2017; 12(8):e0182324.

27. Johansen ME, Johansson PI, Ostrowski SR, Bestle MH, Hein L, Jensen AL, et al. Profound endothelial damage predicts impending organ failure and death in sepsis . Semin Thromb Hemost. 2015; 41(1):16-25.

28. Schouten M, Wiersinga WJ, Levi M, van der Poll T. Inflammation, endothelium, and coagulation in sepsis. J Leukoc Biol. 2008; 83(3): 536-45.

29. Esmon CT, Owen WG. Identification of an endothelial cell cofactor for thrombin-catalyzed activation of protein C. Proc Natl Acad Sci US A. 1981;78(4):2249-2252.

30. Lin SM, Wang YM, Lin HC, Lee KY, Huang CD, Liu CY, et al. Serum thrombomodulin level relates to the clinical course of disseminated intravascular coagulation, multiorgan dysfunction syndrome, and mortality in patients with sepsis. Crit Care Med. 2008; 36(3):683-9.

31. Iasonos A, Schrag D, Raj GV, Panageas KS. How to build and interpret a nomogram for cancer prognosis. J Clin Oncol. 2008; 26:1364-70.

\section{Figures}


Points

10

20

30

40

50

60

70

80

$90 \quad 100$

Age

$\geqslant 57$

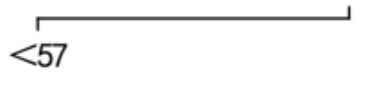

TM

$\geqslant 13.1$

$$
<13.1
$$

Lac

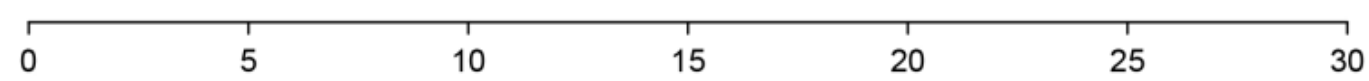

INR

\begin{tabular}{llllllll}
\hline 0.5 & 1 & 1 & 1 & 1 & 3 & 4 \\
\end{tabular}

Total Points

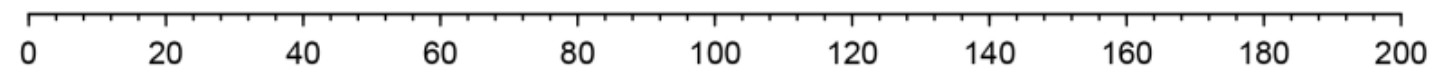

90-day death

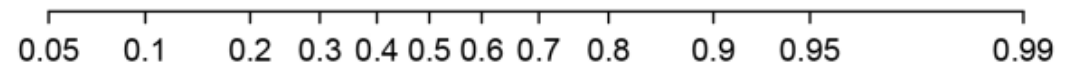

\section{Figure 1}

a nomogram for predicting 90 -day mortality of patients with sepsis. This nomogram was developed in the training cohort, including the Age, INR, Lac, and TM.

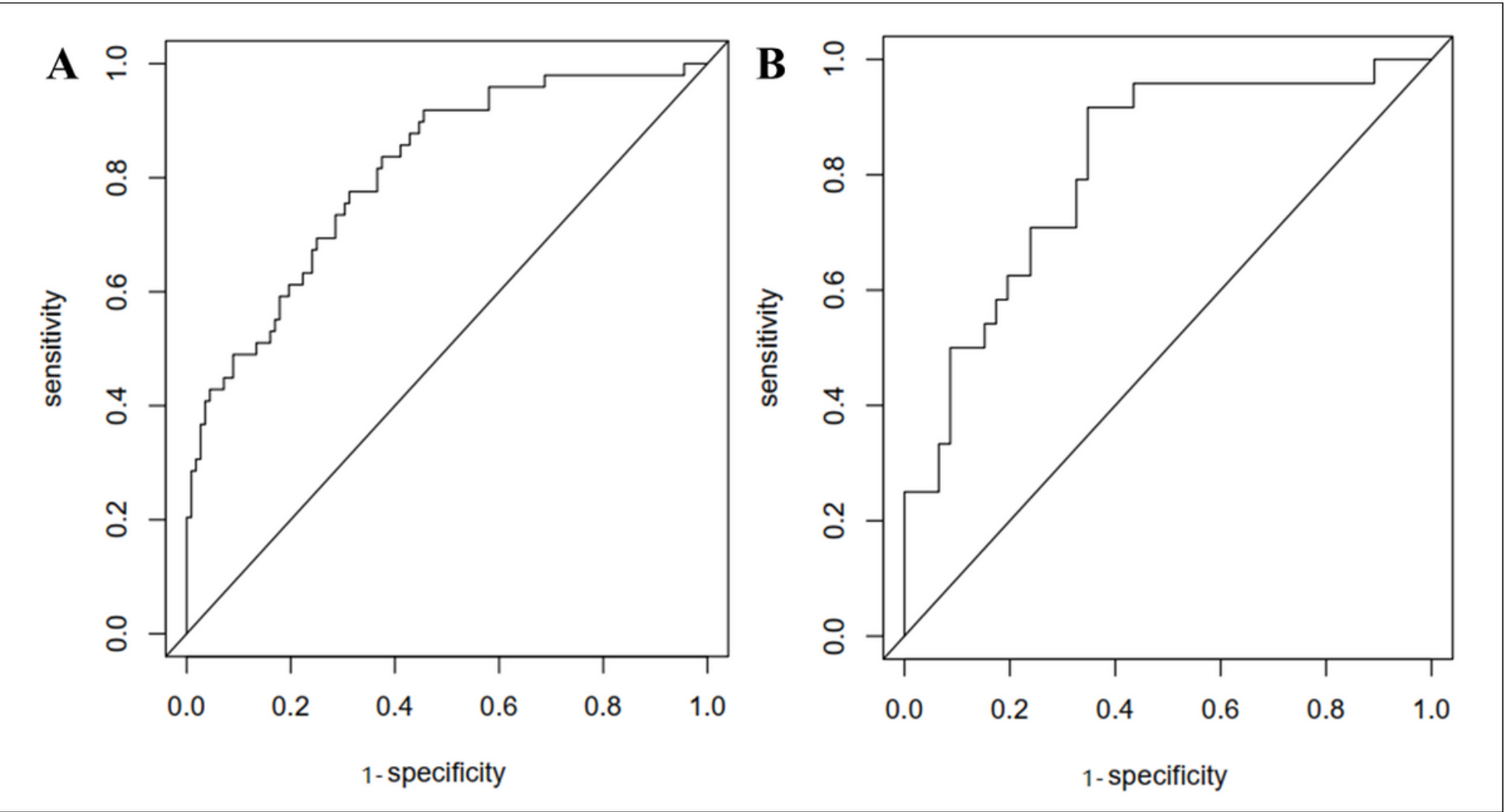

Figure 2 
ROC curve for the nomogram of 90-day mortality in patients with sepsis. A. ROC curve for the training cohort; the AUC was $0.810(95 \% \mathrm{Cl}, 0.739$ to 0.881$)$. B. ROC curve for the validation cohort; the AUC was $0.813(95 \% \mathrm{Cl}, 0.708$ to 0.917$)$.

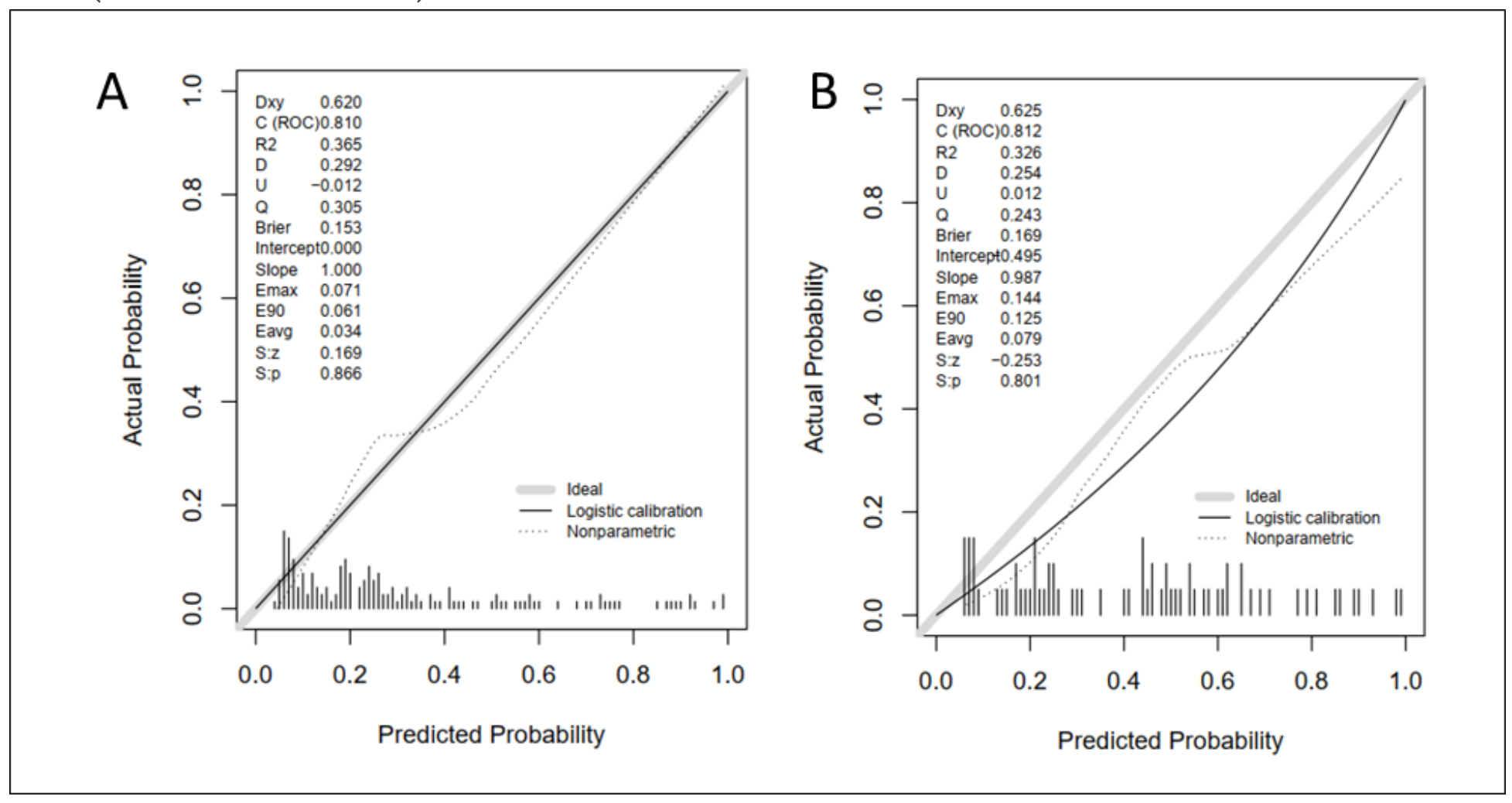

\section{Figure 3}

A calibration plot of the predicted and observed probabilities of 90-day mortality in the training cohort (A) and in the validation cohort (B). 


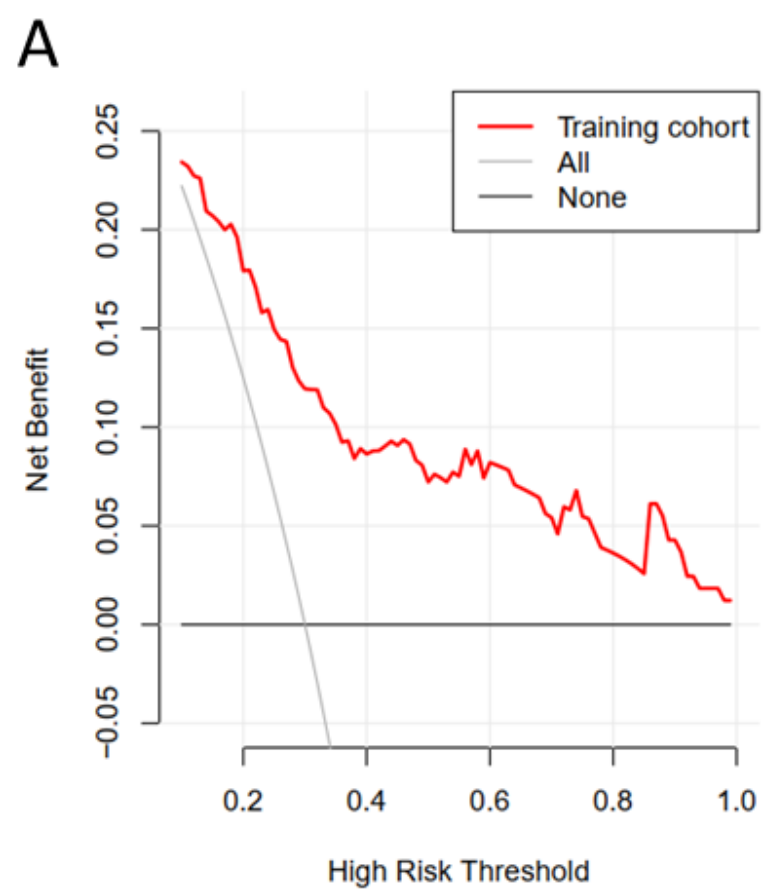

B

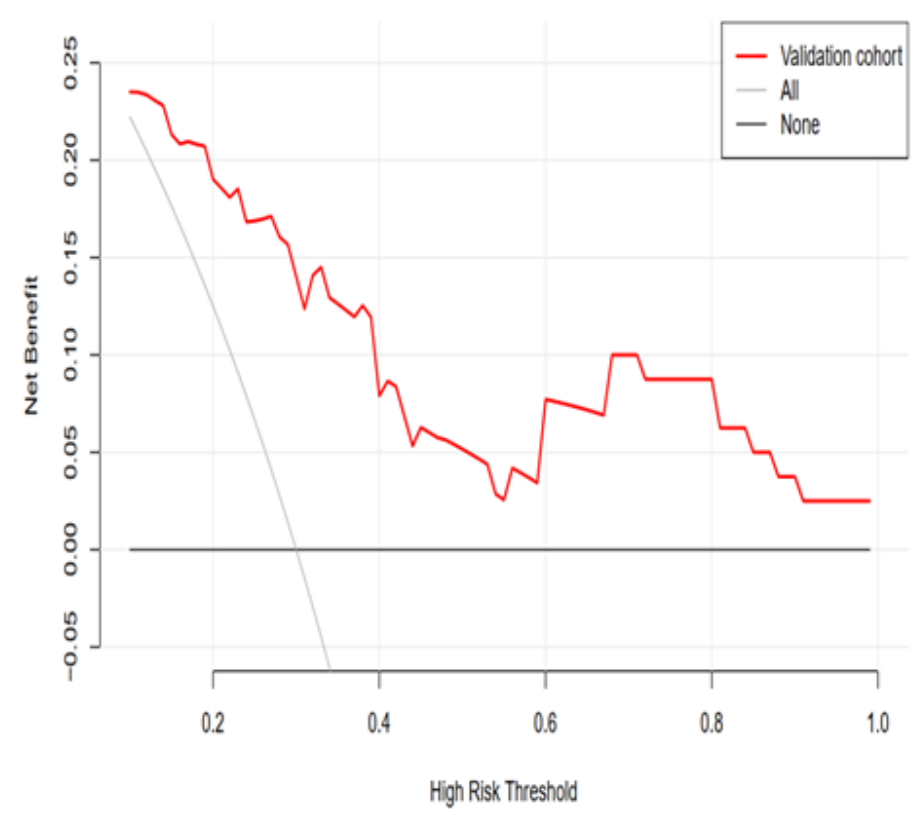

Figure 4

Decision curve analysis of clinical intervention in patients with the nomogram in the training cohort $(A)$ and validation cohort (B). 